\title{
Mujeres y redes masónicas intergeneracionales en México
}

\section{Women and intergenerational masonic networks in Mexico}

\author{
Marco Antonio García Robles \\ Universidad Autónoma de Aguascalientes, México \\ marcogarciarobles@gmail.com
}

Recepción: 10 de abril de 2020/Aceptación: 5 de mayo de 2020

doi: https://doi.org/10.15517/rehmlac.v12i1-2.41375

\section{Palabras clave}

Masonería; México; mujeres; familia; redes.

\section{Keywords}

Freemasonry; Mexico; Women; Family; Networks.

\section{Resumen}

A lo largo del siglo XIX hubo personajes que ostentaron el poder político en México y cuya influencia alcanzó a las élites regionales, mediante sus posiciones en las logias de diferentes ritos, pero también gracias a las redes familiares construidas en torno a mujeres destacadas en el ámbito social. Así pues, en el presente texto se explora una lectura de la historia desde el género y se evidencia la existencia de genealogías vinculadas a las masonerías.

\section{Abstract}

Throughout the 19th century, there were people who held political power in Mexico, whose influence reached regional elites through their positions in the lodges of different rites but also thanks to family networks built around outstanding women in the social sphere. In the present text, a reading of history is explored from the gender perspective. Also, there is an existence of genealogies linked to Freemasonry that is proven. 


\section{Introducción}

¿Cuáles son los nudos que unen las redes de las élites decimonónicas en México? De la investigación doctoral de la que surge este texto, ahora se puede afirmar que por lo menos en el bando liberal de la política, es constante la participación de actores clave en la masonería o mejor dicho, en las diferentes modalidades y ritos de esta sociabilidad. Empero, uno de los retos de la investigación fue elucidar las formas en que se construyeron los vínculos que permiten explicar mejor algunos hechos de la historia nacional.

Una de las respuestas que aparentemente era obvia es la del parentesco, ya que los esbozos de trabajo genealógico confirmaban la familiaridad y confianza expresada por algunos de los personajes estudiados en sus documentos, principalmente misivas. No obstante, en ocasiones resultó complejo dar cuenta de las ligas consanguíneas o adquiridas por la vía religiosa o civil. Es aquí donde la pertenencia a una logia brindó en no pocas ocasiones la solución al entramado que permitía explicar algunas actuaciones públicas.

Sin embargo, para algunos sucesos indagados desde lo regional - específicamente para los estados de Aguascalientes y Zacatecas - faltaban elementos que dieran cohesión a esta visión de los acontecimientos. La tesis de referencia ensayó con el análisis de las relaciones entre arte, prensa y poder, a partir de los testimonios discursivos de los masones en varias generaciones o si se prefiere, periodos de implantación, evolución y consolidación de las variantes de la francmasonería especulativa. Durante el trabajo de indagación y redacción fue que saltaron a la vista aspectos poco observados por la historiografía tradicional, como la visión de género, donde las mujeres son precisamente un elemento clave en la consolidación de las redes mediante la institución tradicional del matrimonio, o bien, con una participación activa en la educación, el arte y las tertulias. No hay pruebas contundentes de su intermediación en lo político, pero no sería del todo descartable.

En el presente artículo, serán recurrentes los apellidos de ciertas familias como los López de Nava, los Terán Arteaga-Pani y los Chávez. También la centralidad "patriarcal” de Valentín Gómez Farías, pero con vínculos políticos a través de su esposa, Ysabel López Padilla. Dichos nombres pasan de manera directa o indirecta por varias generaciones y etapas de la masonería mexicana, lo que lleva a inferir cierta endogamia y continuación de élites en el poder, o su traslado a otros ámbitos sociales, como el universitario o cultural.

De igual forma, se mostrará una aproximación del pensamiento de masones hacia el sector femenino de la población y se dará cuenta del uso del arte con simbología iniciática para honrar a las cónyuges fallecidas. Para ello se realizó una revisión de periódicos publicados por personas pertenecientes a alguna logia, así como de escritos y transcripciones de discursos de masones en medios gubernamentales. 


\section{Todo queda en familia: Valentín Gómez Farías e Ysabel López de .Nava Padilla}

En un registro bautismal del sagrario de la catedral metropolitana, se puede leer que el 5 de marzo de 1824, el sacerdote Ignacio Ortega bautizó al niño Casimiro de Jesús, nacido un día antes, "hijo de legítimo matrimonio de D. Valentín Gómez Farías, natural de Guadalajara, y de Ysabel Padilla, originaria de Aguascalientes; fue su padrino D. Francisco García, advertido de su obligación".

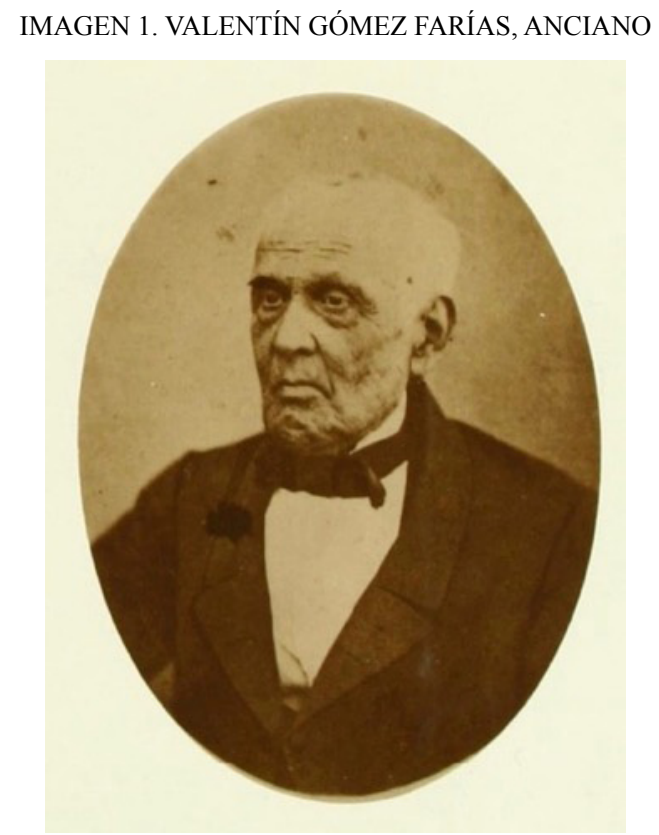

Fuente: Centro de Estudios de Historia de México de la Fundación Carlos Slim

Estas pocas líneas revelan, primero, una estrecha relación entre quien sería gobernador constitucional del estado de Zacatecas, defensor del federalismo, y quien sería el iniciador de la Reforma en México, presidente de la República, así como la primera persona en jurar y fïmar la emblemática Constitución de 1857. "Tata Pachito” y Gómez Farías, masones precursores del Rito Nacional Mexicano. Dice Luis J. Zalce y Rodríguez, autor de Apuntes para la historia de la masonería en México, que:

ingresaron a las filas del Rito Nacional, masones "escoceses" y "yorkinos" de acreditada y fuerte personalidad, entre los cuales citaremos a quienes más tarde, por una u otra causa, adquirirán un sólido prestigio en el bando liberal: Don Francisco García Salinas, verdadero patriarca de las libertades públicas en el estado de Zacatecas, donde su popularidad fue el justo homenaje debido a sus muy altas virtudes privadas y políticas [...] Este fue un constante y valiente enemigo de Santa-Anna, aún en el tiempo del poder más grande que éste llegó a tener. Don Valentín Gómez Farías, don Andrés Quintana Roo [...] el doctor José María Luis Mora [...] dignos hermanos de "Tata Pachito" ...2

1 Localizado en Ancestry.com: Distrito Federal, Centro, Asunción Sagrario Metropolitano, Bautismos de españoles 1824-1827, página 59, registro 266.

2 Luis J. Zalce y Rodríguez, Apuntes para la historia de la masonería en México (México DF: edición de autor, 1959), 101. 
Ahora bien, Ysabel Mariana Josefa López Padilla, a quien Valentín Gómez Farías conoció en su ejercicio profesional como médico en la ciudad de Aguascalientes, de la cual fue diputado ante el Congreso de Zacatecas y presidente del Ayuntamiento, era hija de José Mariano López de Nava Galindo, familia de gran peso histórico en la región, incluyendo gobernadores y diputados locales y federales por Zacatecas y Aguascalientes. Como en varios casos de dicha genealogía, la esposa optó por conservar solamente el apellido "López" haciendo a un lado el compuesto. ${ }^{3}$

Estevan Ávila Mier,+ futuro gobernador de Aguascalientes, fue hijo de José María Ávila -teniente coronel que fue jefe político y gobernador de Aguascalientes en 1837-, se decía sobrino de Valentín Gómez Farías, aunque en realidad el parentesco político lo tenía su media hermana, Dominga Ávila López, que era sobrina de la esposa de don Valentín, Ysabel López.5 Dominga, por cierto, se casó con Rafael Díaz de León, quien también fue gobernador del estado y padre adoptivo de Jesús Díaz de León, masón del que nos ocuparemos más adelante y que asumió en calidad de suplente la titularidad del Poder Ejecutivo.

\section{Los López de Nava}

En enero de 1829, la Legislatura de Zacatecas recibió una misiva firmada en la sala capitular de Aguascalientes por José María López de Nava, quien se congratula de la instalación del Congreso. A decir de algunos autores, este "patriarca liberal” ${ }^{6}$ trabajó en el Rito Nacional Mexicano, ${ }^{7}$ aunque no hay menciones en textos masónicos que lo ratifiquen. Sin embargo, la carta contiene metáforas comunes a los discursos masónicos, con imágenes relativas a elementos constructivos, asociando a los diputados con los bloques labrados de una bóveda:

Semejante la sociedad a una bóveda que se mantiene por una recíproca compresión de las dovelas que la componen, cada una de las partes de aquella debe mantener en justo equilibrio para que el edificio se mantenga ajustado y sólido, concretándose esta unión a las facultades físicas y morales de cada uno de los individuos que lo componen, contribuyendo de este modo a su solidez y conservación, y al indispensable nivelamiento sin permitir desunión alguna; porque sucediendo ésta, por una ley de la naturaleza debe desplomarse y sucumbir al estado de ruina.

Estas meditaciones ocupaban a cada uno de los individuos que actualmente componen al Ayuntamiento de Aguascalientes, originadas precisamente de la triste ruta que presentaba la República Mexicana, agitada por sacudimientos desagradables originados de la desunión de las dovelas que componen su majestuosa bóveda: la amargura abundaba en el horroroso cáliz

3 Tomado de Geneanet, https://gw.geneanet.org/genemex?lang=es\&iz=37646\&p=isabel\&n=lopez+padilla

4 Aparece con esta ortografía en su acta de bautizo, localizada por Miguel Ángel Lozano Ángeles: Archivo de la parroquia del Sagrario antes de la Asunción, Bautizos, Aguascalientes, México, vol. 71, años 1826-1828, foja 343f, en www.familysearch.org

5 Miguel Ángel Lozano Ángeles, a quien agradezco la información, localizó el acta bautismo de Dominga y reparó en el parentesco con Estevan Ávila: Archivo de la parroquia del Sagrario antes de la Asunción, Bautizos, Aguascalientes, México, vol. 64, años 1817-1819, foja 142v, en www.familysearch.org

$6 \quad$ Así lo llama el historiador aguascalentense Jesús Gómez Serrano.

7 José María Mora Ruiz, "Obra de Jesús Terán a 125 años de su muerte”, en Memoria. Homenajes a Jesús Terán, ed. Guadalupe Appendini (México DF: Gobierno del Estado de Aguascalientes, 1991), 49. Desafortunadamente, el autor no proporciona fuentes, de hecho, reiteradamente establece como sinónimos "liberal" y "masón”, proceder incorrecto porque uno no es condicionante del otro. 
[ilegible] que por donde quiera se hallaba pronto para angustiar el espíritu del menos patriotå

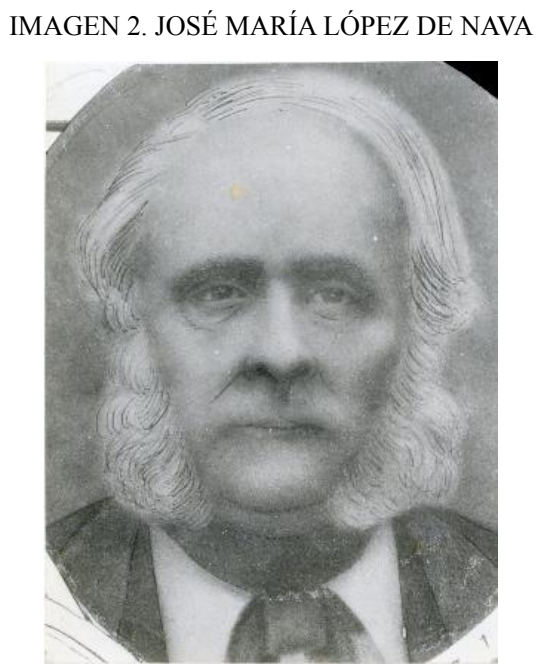

Fuente: Biblioteca Pública Central Centenario Bicentenario de Aguascalientes, Archivo Alejandro Topete del Valle, Fototeca.

Cabe mencionar que la familia López de Nava era terrateniente en la zona de Huejúcar, hoy municipio de Calvillo, y que varios de sus integrantes ocuparon cargos públicos a lo largo del siglo XIX, tanto en Zacatecas como Aguascalientes. Por lo menos de un par de ellos podemos asegurar su filiación masónica: Pedro José López de Nava, primer gobernador del estado de Zacatecas, y Agustín López de Nava, ${ }^{10}$ como diputado. En la época de la Reforma e intervención francesa, consideramos que también formó parte de alguna logia Jesús Fructuoso López de Nava, recordado por su apelativo como escritor, Jesús F. López. No hay documentación masónica que lo pruebe, pero sí hay misivas de la época que lo acusan de masón, fue muy amigo de su compañero legislador federal Francisco de Paula Gochicoa, que llegó a gran luminar del Rito Nacional Mexicano y, en su periódico El Fandango, llegó a escribir de manera irónica sobre la masonería, lo que revela su conocimiento del tema y un perfil anticlerical muy particular de los miembros de esta modalidad masónica"1.

\section{José María Chávez y Jesús Terán}

En la historia de Aguascalientes se cuenta como a uno de sus principales próceres a José María Chávez Alonzo, a quien se le recuerda por encabezar como gobernador a un pequeño ejército contra soldados franceses durante la Intervención y por su fusilamiento en 1864, en Malpaso, Zacatecas. Para muchos liberales de la época, algunos de ellos iniciados en la masonería, la prensa fue una de las formas en que difundieron sus ideas, o bien, hicieron de ella

8 Carta de José María López de Nava al Congreso de Zacatecas, 12 de enero de 1829, en: AHEZ, Fondo Poder Legislativo, Correspondencia, Ayuntamientos, exp. s/n.

$9 \quad$ Beatriz Rojas, Las instituciones de gobierno y la élite local. Aguascalientes del siglo XVII hasta la Independencia (Zamora: El Colegio de Michoacán, 1998), 93.

10 Marco Antonio Flores Zavala, "El grupo masón en la política zacatecana, 1880-1914” (Tesis de maestría en historia, El Colegio de Michoacán, 2001), 49.

11 Jesús F. López, "El culto a Satanás", El Fandango. Periódico político y demócrata, año III, no. 15, Aguascalientes, 19 de enero de 1896, 1-3. 
una forma de intentar "ilustrar a las masas". En algunos casos, es probable que la labor de impresor, periodista o escritor haya catapultado a estos individuos al ámbito político, como el caso de Chávez, quien en múltiples testimonios deja ver su interés por la formación de los artesanos, gremio del que él mismo se consideraba parte. En palabras del médico Pedro de Alba:

El periódico que fundó Terán se llamaba El Crepúsculo; tenía un carácter literario, humanístico y docente. El de Chávez se llamó El Artesano, y en sus páginas se publicaban artículos sobre las artes y oficios de su tiempo. Terán dio nueva vida al Instituto de Ciencias, al grado de que se le considera como su fundador, en tanto que Chávez consagró sus empeños en el establecimiento de talleres para los hijos del pueblo. Su ideal supremo fue impulsar la exposición de agricultura, ganadería, industrias y minería; una de las efemérides más gloriosas de Aguascalientes fue la de haber abierto su primera exposición regional hace más de un siglo, como voz de aliento en medio del retroceso y del derrotismo que reinaba en la República en 1851.

[...] don José María Chávez fundaba talleres de imprenta, encuadernación, alfarería e hilados y una maestranza para construir carros y coches como aquellos que fundara don Francisco García Salinas en Jerez de Zacatecas. Los talleres de los Chávez no fueron lucrativos; él agrupaba a sus artesanos en sociedades mutualistas y los obreros tenían participación en las utilidades. Los adiestraba en los mejores procedimientos técnicos y los hacía conocer la calidad de los materiales al mismo tiempo que establecía pequeñas industrias cerca de sus talleres principales, a los que puso por nombre "El Esfuerzo"12.

En cuanto a Jesús Terán, este abogado es conocido por formar parte de los gabinetes presidenciales de los masones Ignacio Comonfort y Benito Juárez. De este último, recibió la encomienda como embajador plenipotenciario ante las potencias europeas, con la misión principal de que se retirase el apoyo al emperador Maximiliano de Habsburgo, cuestión en la que ciertamente influyó y de la que falta aún bastante por estudiar. Pero antes de esta labor por el que la historia oficial lo denominó como "el diplomático de la Reforma”, emprendió acciones como diputado y gobernador de Aguascalientes para llevar la educación a la población. Al respecto menciona Pedro de Alba:

Durante la lucha por la soberanía y la épica defensa que hiciera de ella el gobernador Cosío, don Jesús Terán fue un consejero atinado y respetable; cuando sobrevinieron hechos adversos para las fuerzas de la soberanía, se concertó una especie de tregua en la que don Jesús Terán fue el hombre de confianza de todos y se le nombró jefe político de Aguascalientes, sobre la ficción de que debía considerarse como Partido de Zacatecas. Terán demostró su capacidad de gobernante y administrador e hizo un gobierno culto y civilizado. Su preocupación primordial fue la instrucción pública y la enseñanza de las artes y los oficios. Fundó el Instituto de Ciencias y se esforzó por aplicar en dicho establecimiento métodos "modernos"; se pronunció contra la retórica y la escolástica y solía hablar de que "esa turba de abogados y de clérigos fuera substituida por hombres de ciencia, de trabajo y de instrucción”.

$12 \quad$ Pedro de Alba, "José María Chávez", en Letras sobre Aguascalientes, ed. Antonio Acevedo Escobedo (México DF: Libros de México, 1981 [1963]), 86. 
En el Colegio que él organizó y sostuvo se establecieron cátedras de matemáticas, de francés, de literatura y de historia. Abrió la academia de dibujo para los artesanos, en las que había clases de carácter práctico para obreros y empleados y enseñanzas de mecánica y geometría aplicada a las artes ${ }^{13 .}$

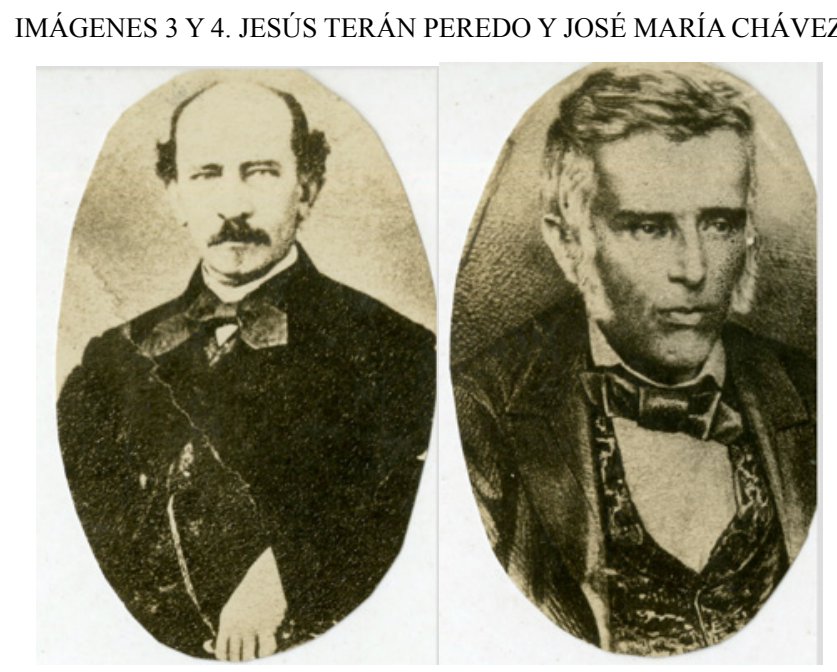

Fuente: Biblioteca Pública Central Centenario Bicentenario de Aguascalientes, Archivo Alejandro Topete del Valle, fondo fotográfico.

En cuanto a la filiación masónica de Jesús Terán y de José María Chávez, el escritor aguascalentense José María Mora Ruiz indica que la tradición masónica dice que José María Chávez y José María López de Nava fueron quienes presentaron en logia del Rito Nacional Mexicano a Jesús Terán Peredo ${ }^{14}$, aunque no presente ninguna referencia de ello; curiosamente, los tres tuvieron en diversos momentos las riendas del estado. En Cartas a fesús Terán, Elizabeth Buchanan y Pilar González señalan como 1843 el año en que Terán ingresó a la masonería presentado por José María Chávez ${ }^{15}$, aunque tampoco citan fuente alguna, pero en los agradecimientos incluyen al señor Mora antes mencionado, por lo que seguramente de él surgió ese dato, aunque queda en especulación si tuvo acceso a documentos masónicos de la época; sin embargo, personas consultadas me comentan que en vida formó un archivo de cierta importancia, cuyo paradero actual se desconoce ${ }^{16}$.

Ratifica la pertenencia de Terán y Chávez al Rito Nacional Mexicano el investigador Carlos Francisco Martínez Moreno, quien también contempla a Ponciano Arriaga, gobernador provisional de Aguascalientes, quien organizó las elecciones en las que salió electo José María Chá-

13 De Alba, "Jesús Terán, un gran señor de la Reforma”, 76-77.

Mora Ruiz, "Obra de Jesús Terán a 125 años de su muerte", 49-50.

Elizabeth Buchanan y Pilar González, Cartas a Jesús Terán (Aguascalientes: Instituto Cultural de Aguascalientes, 1998), 419.

De manera verbal, el director de periódico El Sol del Centro, Mario Mora Legaspi, me comentó que este personaje era un gran apasionado de la historia de Aguascalientes y que tenía las funciones de redactor de discursos para el gobernador del estado, Miguel Ángel Barberena Vega. Por su cuidada forma de no escribir cuestiones internas de la masonería, creo que era iniciado, pero habrá que corroborarlo. También se sabe que era coleccionista de documentos y libros, pero se desconoce el destino de su archivo, del cual hay fragmentos en fotocopias en el Archivo Histórico del Estado de Aguascalientes. 
vez. ${ }^{17}$ En sus Apuntes para la historia de la masonería en México, Luis J. Zalce y Rodríguez afirma que "Don Jesús Terán fue un masón de macisas [sic] convicciones, sin ese jacobinismo chocante de los ignorantes comecuras, lleno de optimismo y de amplia cultura"18. El autor también consigna que el testimonio de afiliación masónica de este liberal lo otorgó Frank E. Mont, "quien al visitar la tumba que guarda los restos de aquél, descubrió en el monumento que la cubre un emblema universalmente conocido" ${ }^{19}$. Traducimos esta alusión como el símbolo de la escuadra y el compás. Aclara, no obstante, que seguramente no fue del Rito Nacional.

\section{Las influencias familiares}

Ya dijimos que el líder masón, varias veces presidente y constituyente de 1857 estaba emparentado con la élite de Aguascalientes y Zacatecas por su esposa Ysabel López de Nava. No es descartable que este vínculo influyera para que Jesús F. López fuera diputado federal en varias ocasiones, quien por cierto mantenía una estrecha comunicación epistolar con José María Chávez durante la intervención francesa. Ambos, con distanciamientos ocasionales, se mantuvieron en contacto con Jesús Terán.

Sin duda queda más claro el uso de la influencia masónica a partir de una historia familiar. Sóstenes Chávez - hijo de José María - fue a capacitarse a la Ciudad de México en las técnicas fotográficas de la época, donde fue alojado por el masón Guillermo Prieto, conocido como "Fidel". La clave para comprender la relación fraternal entre el conocido literato y los Chávez, se encuentra también en las páginas de El Artesano, pues en el número 11, correspondiente al 11 de mayo de 1856, se informa del convenio entre el administrador de la Renta de Correos, Guillermo Prieto precisamente, y la familia en mención, para la conducción del correo entre Aguascalientes y Zacatecas ${ }^{20}$.

Complementa lo anterior una misiva que Jesús Terán envía al titular nacional de Correos, Valentín Gómez Farías, el 27 de octubre de 1855, mediante la cual le recomienda se encomiende la conducción de la valija postal entre Aguascalientes y San Luis Potosí, así como entre Lagos y Zacatecas, a los hermanos Pablo y José María Chávez, de quienes aclara ya poseen el servicio de diligencias entre estos puntos, mismo que podrían cancelar por dificultades económicas si no obtienen la concesión mencionada ${ }^{21}$. Es oportuno mencionar que los Chávez eran fabricantes de carros y, además, poseían un hotel en las proximidades del taller El Esfuerzo, por lo que el negocio -o monopolio- era redondo.

Por cierto, la historiografía de Aguascalientes no consigna una epístola de Estevan Ávila a Valentín Gómez Farías, fechada el 15 de octubre de 1855, que por su importancia trans-

\footnotetext{
17 Carlos Francisco Martínez Moreno, "Masonerías, intervencionismo y nacionalismo en México" (Tesis de doctorado en historia, Universidad Nacional Autónoma de México, 2016), 28.

Zalce, Apuntes, tomo I, 220.

Zalce, Apuntes, tomo I, 221.

El Artesano. Manual Enciclopédico de Industria y Artes, no. 11, Aguascalientes, 11 de mayo de 1956, 87.

Carta de Jesús Terán a Valentín Gómez Farías, Aguascalientes, 27 de octubre de 1855: Universidad de Texas, Colección Latinoamericana Nettie Lee Benson, Genaro García papers, Fondo Valentín Gómez Farías, correspondencia, doc. 4121.
} 
cribimos íntegra, ya que pudo haber influido en la conformación política previa a la Reforma en Aguascalientes:

Muy señor mío y tío de mi mayor aprecio.

Aunque nunca he tenido la honra de escribir a usted, lo hago ahora adjuntándole el periódico que se publica en esta ciudad, en cuya redacción tengo parte, para que impuesto de la verdadera situación que guarda este lugar, se digne en favor de este pueblo hablar al E. señor general Álvarez a fin de que S. E. tome las más acertadas providencias nombrándonos un gobernador que a las ideas liberales una las simpatías públicas.

En este Estado serán recibidas con beneplácito cualquiera de las personas siguientes: Lic. D. Felipe Cosío, D. José María Ávila (mi hermano) ${ }^{22} 0$ D. Jesús Terán, aunque este último es de los llamados moderados.

Inútil es decir a usted cuáles son mis ideas políticas, pues se hallan consignadas en el impreso que le acompaño.

Esta ocasión me proporciona ponerme a sus órdenes como su atento sobrino y seguro servidor que afectuoso su mano besa.

Estevan Ávila ${ }^{23}$.

No sobra decir que el masón Felipe Cosío fue elegido gobernador, pero ante su intempestiva muerte asumió el cargo Jesús Terán. Interinamente, cubrió algún período José María Chávez y años después de forma constitucional. A partir de 1860 le tocaría a Estevan Ávila presidir los destinos de Aguascalientes, con alternancias y altibajos. Por cierto, es por una carta interceptada a este último, que se ratificaría la pertenencia a la masonería de Chávez y de Jesús F. López, pues en un evidente conflicto político con ellos, expresa que seguro acabarán como aliados de los franceses por su asistencia a las logias, lo que crípticamente enuncia como "van al sol que nace ${ }^{24}$ " y puede cotejarse en liturgias del Rito Nacional Mexicano y de York, en cuanto a los ornamentos de los templos y los que se les colocan a los recién iniciados.

\section{¿Masonería femenina en Aguascalientes?}

En el período de la Gran Dieta Masónica del Rito Escocés Antiguo y Aceptado (REAA) de los Estados Unidos Mexicanos, con Porfirio Díaz como dirigente, entre 1892 y 1895, hubo al menos 24 logias de mujeres o mixtas en 13 entidades federativas, pero a raíz de la queja de algunas logias vinculadas con potencias extranjeras, se tuvo que prohibir esta práctica, según lo con-

\footnotetext{
22 Cabe mencionar que Estevan no fue el único miembro de su familia que solicitó favores a Gómez Farías, pues sus hermanos José María (del mismo nombre que su padre), así como Miguel, le solicitan su intervención en diferentes asuntos del ámbito local (las misivas se encuentran en el fondo inmediato anterior citado).

23 Carta de Estevan Ávila a Valentín Gómez Farías, Aguascalientes, 15 de octubre de 1855: Universidad de Texas, Colección Latinoamericana Nettie Lee Benson, Genaro García papers, Fondo Valentín Gómez Farías, correspondencia, doc. 4187.

24 Carta de Estevan Ávila a Pedro P. Adame, protocolizada por Procopio Jayme a petición de Martín W. Chávez, 1862, BPCCB, AATV, Siglo xIx, Documentación Oficial José María Chávez, exp. 971, 2v.
} 
signa Carlos Francisco Martínez Moreno en su tesis doctoral25.

Una de las líderes principales de esta masonería femenina fue Laureana Wright González de Kleinhans, con el nombre simbólico de "Calíope", fundadora de Violetas del Anáhuac, y oradora adjunta de la Gran Logia "Valle de México". Ella era suegra del secretario de la Gran Dieta, Ermilo G. Cantón, quien estaba casado con la masona Margarita Kleinhans "Euterpe". Eran compañeras de Matilde Petra Montoya Lafragua, "Clío”, primera mujer recibida de médico en $1887 .{ }^{26}$ No pasa desapercibido que las masonas mencionadas adoptaron como nombres simbólicos el de las musas correspondientes a la elocuencia, poesía y belleza (Calíope), la música (Euterpe) y la historia (Clío). Evidentemente, aludieron a las divinidades griegas inspiradoras de las artes, actividades que ejercieron ${ }^{27}$.

¿Qué tiene que ver "Calíope" con Aguascalientes?, después de morir, se publicó su libro Mujeres notables mexicanas ${ }^{28}$, con decenas de biografías entre las que incluyó a Julia Delhumeau, viuda de Bolado, y Antonia López de Chávez, dos señoras de Aguascalientes dedicadas a la educación. Entre las reseñadas hay integrantes de sociedades secretas, masonas y esposas de masones; de profesiones tales como profesoras, escritoras, religiosas, artistas y otras más. Jesús Díaz de León, en El Instructor, dejó testimonio de la visita de Laureana Wright, tras calificar como digno el papel de varias mujeres en la literatura mexicana:

Últimamente hemos sido honrados con la visita de "Las hijas del Anáhuac" de México, cuya importante publicación está dirigida por la señora Laureana Wrigth de Kleinhans y apoyada con la colaboración de distinguidas escritoras mexicanas cuyas producciones honran nuestra literatura nacional y hacen acreedoras a la estimación general a sus autoras ${ }^{29}$.

Es posible que la citada visita tuviera carácter promocional de la publicación que semanas más tarde cambiaría su nombre por el de Violetas del Anáhuac, puesto que, en el Fondo de Instrucción Pública del Archivo Histórico del Estado de Aguascalientes, hay oficios donde Antonia López, directora del Liceo de Niñas, entera a la autoridad municipal de la suscripción a la citada publicación ${ }^{30}$, así pues, es lógico que "Calíope" conociera a la profesora. Tampoco se puede descartar el auxilio de las logias de Aguascalientes en la visita reseñada por Díaz de León, ya que como dije, Ermilo G. Cantón fue un importante líder de la masonería en el país, pues presidió la gran logia “Valle de México” y dirigió por años el Boletín Masónico, que se convirtió en el órgano oficial de la Gran Dieta Masónica de los Estados Unidos Mexicanos ${ }^{31}$.

Un razonamiento inmediato es suponer si los esposos de las reseñadas estuvieron ini-

\footnotetext{
25 Martínez Moreno, "Masonerías", 213-214.

26 Martínez Moreno, "Masonerías”, 213-214.

27 Marcelo Ferrando Castro, "Las Musas griegas", RedHistoria, 18 de marzo de 2018, https://redhistoria.com/mitologia-griega-las-musas-griegas/

Laureana Wright de Kleinhans, Mujeres notables mexicanas (México DF: Secretaría de Instrucción Pública y Bellas Artes Tipografía Económica, 1910).

29 [Jesús Díaz de León], "Las hijas del Anáhuac", El Instructor, año IV, no. 9, enero de 1888.

30 Esta información me fue proporcionada por Dolores García Pimentel, quien, al momento de redacción de la presente tesis, se encontraba en el proceso de catalogación del Fondo de Instrucción Pública del AHEA.

31 Para mayor referencia de la trayectoria de Cantón puede consultarse la tesis de Martínez Moreno, Masonerías.
} 
ciados en la masonería. Serían los casos de José Bolado ${ }^{32}$, lo cual suena probable pero no está documentado, y de Rafael Ignacio Chávez, hermano de José María del mismo apellido, plausible por la cuestión familiar, pero de lo que tampoco hay datos probatorios. Lo que sí es interesante, en ambos casos, es que tenían parientes políticos masones. Para la época referida, doña Antonia debería conocer por lo menos al masón Gil Chávez - hijo de José María Chávez-, que vendría a ser su sobrino político. En el caso de Julia, su hijastra Ángela Bolado, era esposa de Jesús Díaz de León - sobrino nieto de Valentín Gómez Farías- y estaba vinculada con el masón José Herrán, sobrino de su esposo.

IMAGEN 5. ANTONIA LÓPEZ VIUDA DE CHÁVEZ

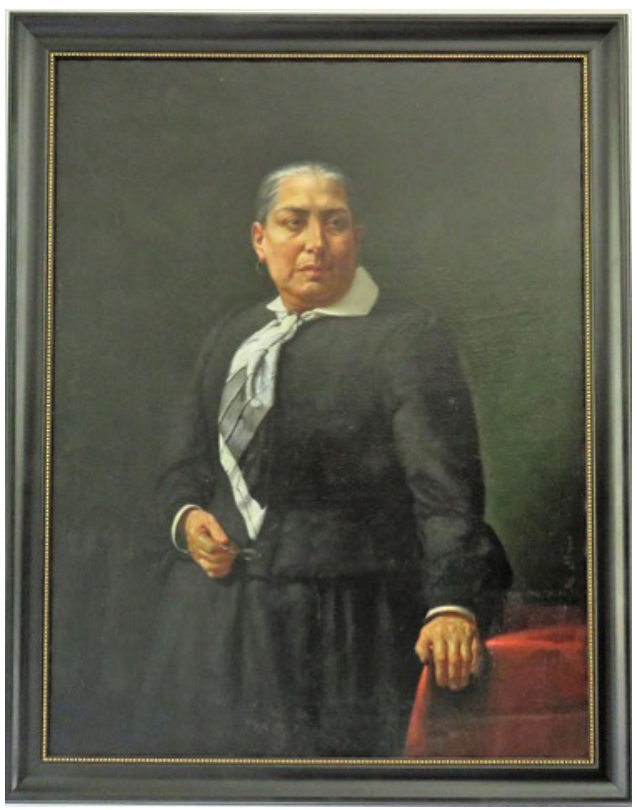

Fuente: Fotografía de Luis Gerardo Cortez, retrato en la Escuela Normal de Aguascalientes.

Lo más probable es que Antonia y Julia no fueran masonas, pues no se conoce que hubiese existido una logia femenina en Aguascalientes, aunque indudablemente fueron mujeres excepcionales para su tiempo, cuando la concepción de los roles femeninos estaba muy encasillada en el hogar y la crianza de los hijos. En ese círculo ilustrado, rodeadas de masones, estas mujeres pudieron sobresalir en esferas relativamente vedadas a los hombres. Es el caso de Julia Delhumeau y su hijastra Ángela Bolado, que pudieron desarrollar libremente sus aficiones artísticas. De la primera, veamos qué consignó Laureana Wright:

A la edad de 12 años tuvo que ir a vivir con su familia en una Fábrica apartada de la ciudad [de México], donde sus hermanos estudiaban la mecánica, permaneciendo allí seis años, y aprovechando la soledad a que se veía reducida en beneficio del aprendizaje que se había

32 Por ejemplo, la alocución fúnebre pronunciada por Melquiades Moreno da indicios de ello, por la redacción en castellano (uso de la conjugación con el vos) todavía usado entre los masones escoceses mexicanos; por la utilización de expresiones sustitutivas de "Dios" como "supremo creador", "supremo remunerador", etc. Desafortunadamente tampoco poseo datos para corroborar la adhesión del profesor citado en alguna logia. El texto de su intervención en las exequias puede consultarse en El Republicano del 11 de agosto de 1888,3 . 
propuesto. Su carácter retraído y propenso a la melancolía le hacía preferir el estudio a toda otra distracción, y aunque teniendo que cumplir los imprescindibles deberes de esposa y madre, no solo siguió cultivando la lectura y traducción de los dos idiomas que tanto le agradaban [inglés y francés], sino que, sola también y sin maestros de literatura, comenzó a cultivar las bellas letras dando a luz algunos artículos descriptivos, que desde luego revelaron la claridad de su inteligencia. Alentada por la facilidad con que escribía comenzó a componer piezas de teatro, alcanzando completo éxito en este género, quizá el más difícil de todos, y el que mayores escollos presenta ante la aceptación pública33.

¿Y qué nos dice la masona “Calíope” de Antonia López viuda de Chávez? Esta es la respuesta en su libro, que, por cierto, incluyó los retratos de las biografiadas:

La Señora López de Chávez renunció entonces la dirección de la Escuela; pero su esposo que aplaudía y fomentaba su inclinación al estudio, le pagaba profesores que le trasmitieran los conocimientos que antes por falta de tiempo y elementos no había podido adquirir. Entonces se perfeccionó en el Dibujo, aprendió Astronomía, Inglés y algunas otras materias de instrucción secundaria, consideradas en esa época como inaccesibles para la mujer; siendo objeto de admiración en la sociedad porque era un modelo de orden en su casa y un modelo de aplicación en el estudio [...]

Lo que ocupaba de preferencia la atención de los fundadores del Liceo [de Niñas], era la persona en que debieran fijarse para la dirección de él; pues de su acertada dirección dependía, casi en totalidad, el buen resultado de su proyecto. Siéndoles bien conocidas las aptitudes de la Señora López, de acuerdo todos, resolvieron nombrarla Directora del Liceo, asignándole un insuficiente sueldo porque no se contaba sino con muy exiguos recursos. La Señora López de Chávez desistió de su desahogada posición; aceptó sin vacilar su nuevo encargo y entonces vióse con claridad todo el valer, toda la abnegación y energía que guardaba su noble alma. Luchó contra la opinión pública que dudaba de la dedicación de los profesores porque no disfrutaban sueldo y criticaba la enseñanza asegurando que sólo se enseñarían las alumnas a ser fatuas y $\operatorname{coquetas}^{34}$.

Nos dice el teórico R. W. Connell que históricamente el concepto de masculinidad se ha construido recientemente de manera relacional, al oponerlo a la feminidad. Señala que "a las mujeres se les consideraba claramente distintas a los hombres, pero la diferencia residía en que se les consideraba representaciones incompletas o inferiores de un mismo carácter..." y añade que, respecto a caracteres cualitativamente distintos entre los sexos, "esta noción acompañó a la ideología burguesa de las ‘esferas separadas’ del siglo XIX"35.

Básicamente, el pensamiento que orientó la creación del Liceo de Niñas e instituciones similares era formar a buenas madres, hermanas e hijas. Sobre Antonia López viuda de Chávez, el masón Jesús Bernal publicó en la respectiva “Necrología” de El Republicano, lo siguiente

\footnotetext{
$33 \quad$ Wright, Mujeres notables, 412-414.

Wright, Mujeres notables, 386-389.

R. W. Connell, Masculinidades (México DF: Universidad Nacional Autónoma de México, 2003), 104.
} 
"La ilustre directora de un plantel modelo donde la mujer se inspiraba en los sanos preceptos de la moral y la virtud, ya no existe" ${ }^{36}$, cuestión en la que insiste con redacciones diversas. Es significativo que lo diga una persona que conocía como una de las acepciones de la masonería, la de "es el estudio de la filosofía, y en particular de la moral para conocer y practicar la virtud". No quiero decir con ello que la formadora de profesoras haya sido masona, pero como en otros ámbitos, es posible que se le reconociera como alguien que cubría el perfil de tal, sin el nombramiento y la colocación respectiva del mandil. El mismo Bernal, en ocasión de una graduación, nombra con un llamativo calificativo a las egresadas de la normal: "tres hermosas sacerdotisas de la instrucción y el progreso, que sabrán, a no dudarlo, trasmitir el caudal de sus vastos conocimientos entre todas las clases de nuestra sociedad, cumpliendo así con la noble cuanto grandiosa misión que pesa sobre ellas”37. Con una visión más tradicional, nos encontramos con la concepción del masón Manuel Gómez Portugal sobre el papel de la mujer:

Formareis, siendo ilustradas, la parte integrante mas hermosa de nuestras sociedades; y aquellas palabras que el gran trágico griego pone en boca de uno de sus personajes: de que las fatigas del esposo sustentan a la mujer ociosa en el hogar; se cambiarán en estas otras: La mujer ilustrada es el apoyo mas fuerte del hombre en su continua lucha contra la naturaleza. ${ }^{8}$

En la misma línea, es interesante conocer el pensamiento del editor de El Instructor, profesor del Instituto Científico y Literario, y masón, quien al igual que su patrocinador, el gobernador Alejandro Vázquez del Mercado, alcanzó el grado $30^{\circ}$ en el Supremo Consejo del Rito Escocés Antiguo y Aceptado. Esto es lo que pensaba Jesús Díaz de León:

El feminismo, cuyo nombre nos proponemos sustituir con el de ginemaquismo, es una evolución especial en la literatura de nuestra época, que se hace cada día más dominante en las ideas que flotan en la atmósfera de la vida pública de todos los pueblos a medida que la mujer, sintiéndose dueña de su pensamiento, comienza a hacer uso de esa libertad que las costumbres le van concediendo, no sin pasar por duras pruebas de censura y hasta ridículo antes de poder imponerse cada personalidad femenina. Hoy por hoy, como la excepción de su sexo, bien sea que tome la pluma para lanzarse al periodismo, bien que se aliste bajo la bandera de las profesiones científicas o que aspire a las coronas que ofrecen las artes liberales.

El ginemaquismo es en mi concepto, la fórmula sintética de la evolución sociológica de la mujer misma, que asume la responsabilidad de su misión como compañera del hombre según el verdadero concepto del cristianismo condensado en aquellas palabras de San Pablo, "no te damos sierva sino compañera", y adaptando esa misión a las aspiraciones de esta edad histórica, como colaboradora en la obra del progreso humano, definiendo el papel que le corresponde con tal carácter y esforzándose, en fin, por realizar en la vida civil y en la vida doméstica todas las doctrinas a que ha dado lugar el conocimiento de su adaptación a los medios [...] social intelectual y afectivo, para cuya función ella, la mujer, tiene mil veces más plasticidad que el hombre, y de aquí su mayor importancia como educadora, y por lo tanto,

36 Jesús Bernal, "Necrología", El Republicano, no. 944, Aguascalientes, 2 de junio de 1895, 2.

37 Bernal, "Exámenes de recepción”, El Republicano, no. 701, Aguascalientes, 12 de octubre de 1890, 1.

38 Manuel Gómez Portugal, "Discurso de estatuto pronunciado en la distribución de premios del Instituto de Ciencias", El Republicano, no. 929, Aguascalientes, 17 de febrero de 1895, 1. 
el interés siempre solícito que debe despertar como educanda.

Ginemaquismo quiere significar, la defensa de la mujer por la mujer misma, en cuya magna empresa coadyuva el hombre, como panegirista o como detractor no menos que como filósofo y como sabio para ilustrar los detalles que a cada momento surgen en los problemas que ofrece la emancipación de la mujer ${ }^{39}$.

En la foja 15, solo escrita en la cara del frente, hay un texto inconcluso titulado “¿Qué es la mujer?” Este corresponde al primer número del año 24 de El Instructor ${ }^{40}$, lo que nos da una referencia de la época en que fue escrito el anterior texto.

Si revisamos las alocuciones, artículos y poemas publicados en El Republicano, periódico oficial del gobierno de Aguascalientes entre 1890 y $1895^{41}$, se localizan apenas una decena de escritos, que se tratan casi en todos los casos, de participaciones de hijas de los miembros de la élite porfiriana o maestras en algún acto público, o se trata de alguna colaboración extranjera. También, de manera ocasional, se recordaba en El Republicano la participación de algunas mujeres en asuntos relevantes de Aguascalientes, como cuando los franceses estuvieron a punto de fusilar a varios liberales, entre ellos a Jesús F. López, quien dedicó su libro Pot pourri, "al bello sexo de Aguascalientes en testimonio de gratitud", además de dar a conocer la carta que los exonerados dirigieron a la esposa del mariscal François Achille Bazaine, conocida en México como Pepita Peña de Bazaine:

La sociedad de aquella capital especialmente, y con una solicitud grande del bello sexo, se empeñaron en impetrar para nosotros el indulto; hubo el acierto de escogeros como medianera, interponiéndose a vuestro lado entre las víctimas y un patíbulo que levantaba, más que el rigor del Código militar francés, la ceguedad y la desconfianza injustificables.

Vos señora, alcanzasteis nuestro perdón. A impulsos de un corazón sensible habéis mostrado, una vez más, que la compasión hacia el que sufre es la parte angélica de vuestro sexo.

Considerad, señora, cuál será nuestra gratitud si al acariciar a nuestros hijos recordamos que todo os lo debemos: desde el fondo de nuestro calabozo no cesamos de bendecir vuestro nombre, y de rogar al Ser Supremo derrame sobre vos inacabables dichas ${ }^{42}$.

En fin, ya será hasta entrado el siglo Xx cuando se pueda observar en un papel protagónico a algunas masonas, como el caso de la española Belén de Sárraga, grado 33 de la masonería escocesa, quien estuvo en Aguascalientes en junio de 1923 para impartir una conferencia, promovida por logias y líderes sindicales ${ }^{43}$. Tal vez llegó a pasar por la mente de algunos masones que algunas mujeres entraran a las logias, aunque lo más probable es que no ocurriera en

\footnotetext{
39 Jesús Díaz de León, "Ginemaquismo" (manuscrito), Archivo Histórico de la UNAM, Fondo Jesús Díaz de León, caja 6, ramo: Obras y traducciones, doc. 34, ff. 2f-3f.

“¿Qué es la mujer?”, El Instructor, año XXIV, no. 1, Aguascalientes, mayo de 1907, 1.

Es el periodo en el que las logias de Aguascalientes trabajaron bajo la Gran Dieta dirigida por Porfirio Díaz. “Advertencia”, en Jesús F. López, Pot pourri, tomo I (Aguascalientes: Imprenta de El Águila, 1897), 1.

Le agradezco la referencia al maestro Alain Luévano, quien localizó el oficio donde la Confederación de Gremios Obreros le solicita al gobernador del estado apoyo para la citada actividad: AHEA, Secretaría General, caja 148, exp. 42.
} 
la sociedad tradicional de Aguascalientes.

\section{Las tertulias}

Párrafos antes mencionábamos lo cerrado o pequeño de la élite cultural de Aguascalientes durante el Porfiriato donde, ante la escasez de actividades, se organizaban reuniones de diversa índole, entre ellas las tertulias literarias o musicales. Tras la debacle del lerdismo, se alzó localmente como líder cercano a Díaz, Francisco Gómez Hornedo, quien estaba casado con Josefa Bolado ${ }^{44}$, hija de José Bolado, promotor al igual que Hornedo de la instrucción pública y la cultura, y cuyo padre, Juan José Bolado, aparece como integrante de la Sociedad de Amigos del País de Zacatecas en los años veinte del siglo XIX.

En las reuniones del que podría llamarse el "grupo Hornedo", se contaba con la participación del masón Jesús Díaz de León, casado con Ángela Bolado, así como los hermanos liberales Rafael y Carlos Sagredo (desconozco si eran masones), este último unido en matrimonio con María Carmen Bolado. También acudían los masones Alejandro Vázquez del Mercado, José Herrán -esposo de Josefa Güinchard-, Donato Motta y Manuel Gómez Portugal -esposo de Evangelina Güinchard-. También participaban Ignacio N. Marín (posible masón), Francisco Armería, Gerónimo Aguado y Lares, Marín González, Manuel I. Aguilar y José de la Luz Rubalcava5.

En estas veladas literarias, los asistentes convivían y presentaban sus escritos. Por ejemplo, en 1894 tenían la costumbre de encontrarse cada mes en la casa de uno de ellos. En la reunión del 4 de marzo, Manuel Gómez Portugal ${ }^{46}$ presentó su poema "El origen del beso", en honor de todas las esposas del grupo. En esas reuniones, acostumbraban a hacer una "colecta" entre todos, que era recogida por la esposa del anfitrión para repartirla entre las familias pobres. El historiador Luciano Ramírez Hurtado ejemplifica cómo eran las formas de urbanidad y socialización de la época, al citar la recepción que algunos de los personajes mencionados le dieron a un periodista extranjero:

...para la tercera semana de octubre de 1887 un grupo de notables (Manuel Gómez Portugal, Jesús Díaz de León, Julio Pani, Francisco G. Hornedo, Blas Elizondo, José Herrán, entre otros) dio la bienvenida en la estación del ferrocarril a Mr. Talbott -rico periodista norteamericano, editor y propietario del Railway Age, que viajaba en tren privado por varias ciudades del país, con la intención de recabar información, datos estadísticos sobre industria, minas, agricultura, monumentos e historia de México- y esposa, quienes se encargaron de pasearlos por calles, jardines y varios edificios representativos de la ciudad y cercanías, hacerles la corte e invitarles a tertulias, veladas literarias y banquetes. La crónica es una ventana a la vida social de la élite de la época, con sus reglas de cortesía, urbanidad y buenas costumbres [...]

\footnotetext{
44 Datos tomados de Luciano Ramírez Hurtado, "Ángela Bolado, artista de provincia; su influencia en Saturnino Herrán. Atmósfera artística en Aguascalientes, buenas costumbres y élite socio-cultural durante el porfiriato" (Aguascalientes: versión inédita, 2018), 13.

45 Nota al pie del poema "El origen del beso" de Manuel Gómez Portugal, en El Instructor, no. 12, año X, Aguascalientes, abril de 1894, p. 3 .

46 Observando las relaciones familiares, tiene lógica que el doctor Gómez Portugal gestionara durante la gubernatura de Miguel Güinchard, que se trajeran los restos de su padre Jesús desde San Luis Potosí, para rendirle el respectivo homenaje en su tierra.
} 
El testimonio del Dr. Gómez Portugal (casado con Evangelina Güinchard, esto es, pariente de la madre de Saturnino Herrán), entrañable amigo de Ángela Bolado y el Dr. Díaz de León, no tiene desperdicio; describe con detalles la elegante recepción, el esmerado servicio de té y finos bocadillos, la velada musical, las bebidas espirituosas, los brindis y, en general, el magnífico ambiente que privó esa noche (empezó a las 20:0o horas) y que se prolongó hasta la media noche. Podemos imaginar los preparativos de la reunión, para que todo fuese elegante, gracioso y espléndido pues querían lucirse ante los distinguidos visitantes y quedar bien con las amistades y parientes que les acompañaron ${ }^{47}$.

Este pasaje histórico, más propio de una revista de sociales para la época, habla de la importancia de la formación artística y cultural de la élite. Vemos a las esposas de los masones interpretando arias operísticas, ofreciendo bocadillos, charlando en idiomas diferentes al español con los visitantes, y en este caso en particular, mostrando trabajos de pintura, como los de Ángela Bolado, esposa de Jesús Díaz de León. También damos cuenta de la presencia de la poetisa y maestra del Liceo de Niñas, Julia Delhumeau, esposa de José Bolado, quien saldrá a relucir más adelante.

Lo anterior es una reconstrucción del espacio familiar, pero ¿cómo era la convivencia masculina? Es el escritor Eduardo J. Correa quien nos proporciona las pistas necesarias, en su ineludible Un viaje a Termápolis, que, aunque pretende ser obra de ficción, enumera una serie de personajes, hechos y escenarios históricos reales, cercanos a la séptima década del siglo XIX. Por ejemplo, en "La número 1" cuenta la dinámica en los "mentideros" de las trastiendas:

Los lenguaraces que no logran acceso a la trastienda, tal vez aconsejados por el despecho, difunden la especie de que allí, entre copa y copa, se hace tanta o más política que en un club, y que es donde se confeccionan las listas de los que entre las urnas han de ser favorecidos por el voto popular, así como que con tiempo se prepara la salmuera en que han de adquirir sapidez los candidatos a la gubernatura.

Haya o no en esto exactitud, pues débese convenir en que, cuando determinados rumores adquieren carta de ciudadanía, en el fondo de sus mentiras corre un hilillo diáfano de verdad, no debe asegurarse que los sesudos varones que allí se reúnen se congreguen exclusivamente a discutir sobre cosas trascendentes, convirtiendo la trastienda en areópago $0^{48}$.

Entre los concurrentes habituales, enlista Correa, figuran Francisco G. Hornedo, Alejandro Vázquez del Mercado, Rafael Sagredo, Blas Elizondo, Librado Gallegos ${ }^{49}$, Antonio Salas, José María Peón Valdés, Juan N. Sandoval, Ignacio T. Chávez, José de la Luz Rubalcava, Gil Chávez, el “doctor Camarena”, José Bolado, el licenciado José Nicolás Romero, don Juan C. Portugal, Canuto Díaz, Severino Martínez, Manuel Flores, Celedonio Sánchez, José Herrán, Vicente Berber y Jesús F. López. A "vuelo de pájaro", entre estos nombres hay por lo menos

\footnotetext{
47 Ramírez, “Ángela Bolado, artista de provincia”, 64-66.

48 Correa, Un viaje a Termápolis, 211-214.

49 Este reconocido masón fue padrino de bautizo de Jesús Díaz de León, curiosamente, ambos fueron gobernadores provisionales de Aguascalientes. La referencia respectiva fue localizada por Miguel Ángel Lozano Ángeles: Archivo de la Parroquia del Sagrario antes de la Asunción, Bautismo, Aguascalientes, México, volumen número 92, años 18511852, foja 177 vuelta. En www.familysearch.org
} 
cinco masones, por lo que no habría que descartar que en efecto, se tratase de reuniones de los mismos, para trabajos informales o de simple convivencia, que en términos masónicos podría denominárseles "ágapes". Cabe señalar que el departir con bebidas alcohólicas de por medio, es un uso arraigado en las reuniones de masones, y que incluso, la "libación" es parte de algunos rituales específicos, como las tenidas solsticiales.

Sorprende la denominación final que hace el escritor - de corte católico- cuando habla de que la trastienda se convierte en un "areópago", que en términos estrictos se trata de la “colina de Ares”, un monte en la Acrópolis de Atenas, donde se reunía el consejo real en la antigüedad. El asunto es que, en términos masónicos, se refiere a la "cámara donde se reúnen los masones del grado 30, Caballeros Kadosh"50.

\section{Mujeres y arte}

Jesús Díaz de León fue el encargado de organizar en 1891 en Aguascalientes una exposición de arte, en concordancia con el auge que en el siglo XIX tuvieron las exposiciones internacionales e industriales, que pretendían ser los aparadores de las naciones civilizadas en el contexto mundial. En esta ocasión reseñada en un libro del propio médico51, participó su esposa, Ángela Bolado, quien además de intérprete musical practicaba el arte pictórico. Sobre esta integrante de la élite porfiriana, opina el historiador Luciano Ramírez Hurtado:

al casarse con el doctor Jesús Díaz de León, desempeñó el rol tradicional de esposa y madre, de acuerdo a su clase social acomodada. Pero también es claro que el marido, en una sociedad machista y clasista, le dio libertades para expresarse mediante el arte y exponer sus trabajos, y hasta cierto punto a interactuar con otros grupos y circuitos de arte, muy selectivos por cierto. A ella le tocó desenvolverse en un contexto histórico determinado, completamente dominado por los hombres, en donde el acceso a la cultura era limitado para las mujeres, pero que poco a poco fueron abriendo brecha sobre todo en el Liceo de Niñas ${ }^{52}$.

El doctor, en las memorias escritas en el libro La Exposición de Bellas Artes de Aguascalientes, le dedicó elogios con la pretensión de ser imparcial y que pueden tener algo de cierto, ya que por lo menos se conoce uno de sus lienzos de excelente manufactura y que se trata precisamente del retrato más conocido de su marido ${ }^{53}$.

50 Diccionario breve de la Masonería (Madrid: Fundación María Deraismes, 2010), 15.

51 Jesús Díaz de León, La Exposición de Bellas Artes en Aguascalientes Correspondiente Al XXIX Certamen Celebrado por el Estado (México DF: José J. López impresor, 1891).

52 Luciano Ramírez Hurtado, “Ángela Bolado y Jesús Díaz de León. Una pareja de la élite artística y cultural en el Aguascalientes porfiriano", en Jesús Díaz de León (1851-1919). Un hombre que trascendió su época, coord. Luciano Ramírez Hurtado (Aguascalientes: Universidad Autónoma de Aguascalientes, 2019), 176.

Díaz de León, La Exposición de Bellas Artes, 65-72. 


\section{IMAGEN 6. JESÚS DÍAZ DE LEÓN Y ÁNGEL BOLADO}

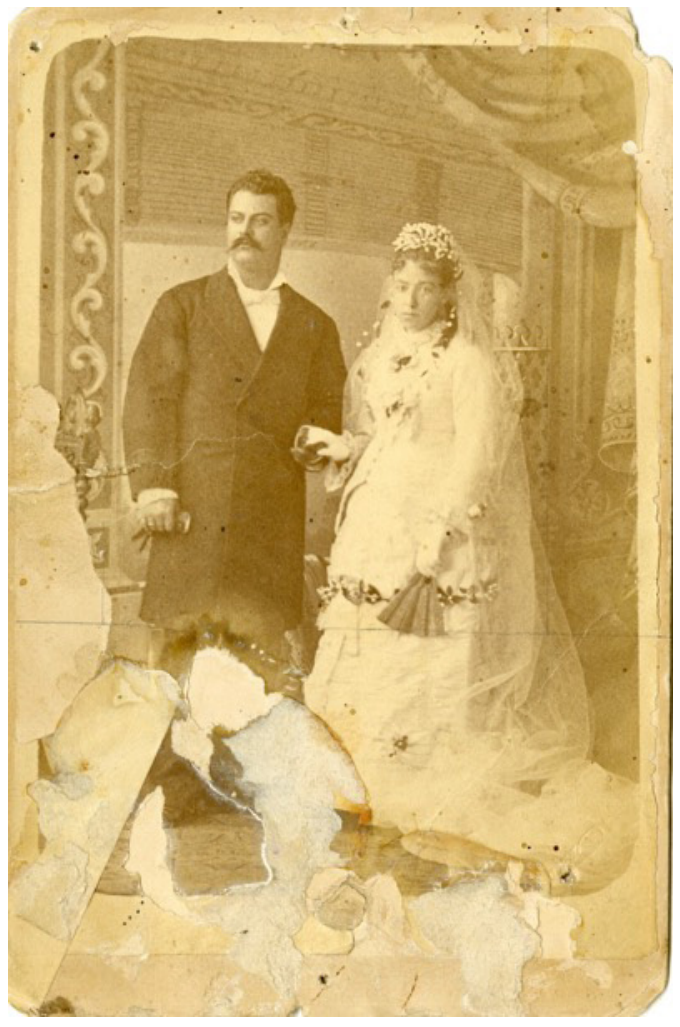

Fuente: Biblioteca Pública Central Centenario Bicentenario de Aguascalientes, Archivo Alejandro Topete del Valle, Fondo Fotográfico.

Hay otro tema que tiene que ver con el arte y que implica indirectamente a Jesús Díaz de León. En el cementerio de los Ángeles, en la ciudad de Aguascalientes, hay un monumento emblemático de la iconografía fúnebre en la masonería. Se trata de la tumba de Mercedes Gutierres [sic], quien fue esposa del masón Donato Motta, marcada con una columna rota de cantera amarilla. El registro de defunción está fechado el 20 de mayo de 1899, aunque se especifica que el deceso tuvo lugar el día inmediato anterior. En el acta aparece como testigo del hecho el masón José Herrán ${ }^{54}$. Del bello conjunto arquitectónico, tenemos la lectura de Lourdes Adriana Paredes Quiroz:

Esas ideas son las que también se transmitieron con los símbolos del monumento funerario de Mercedes de Motta, el transcurso de la vida interrumpido por la muerte, la fragilidad del cuerpo y la fugacidad del tiempo con el ataúd y la corona de violetas a los pies de la tumba; mientras que la palma y el laurel que rodean la columna indican la inmortalidad del alma y el reconocimiento de las virtudes de la finada 5 .

De la maestra también obtuvimos la referencia de la publicación de un poema a cargo del amigo de Donato Motta, Jesús Díaz de León, en El Instructor, a dos meses de acontecido el fallecimiento por intoxicación - no se consignó debido a qué sustancia- de la mujer originaria

54 Ancestry.com: Aguascalientes, México, Registro Civil, Defunciones, 1859-1961, 236.

55 Lourdes Adriana Paredes Quiroz, “Arte funerario en Aguascalientes 1875-1930. La visión sobre la muerte, los discursos visuales: conmemoración y creencias" (tesis de maestría en investigaciones sociales y humanísticas, Universidad Autónoma de Aguascalientes, 2018), 304. 
de Jesús María, Chihuahua. Evidentemente, el hermano masón pretendía la pronta resignación de su maestro de italiano:

Cuando el hombre encuentra una compañera que se identifica con su destino, es la fuerza moral que lo alienta sin cesar en la lucha. Y se siente fuerte, invencible, porque el desaliento jamás se alberga en su alma. Allí está la compañera que sufre también el flujo y reflujo de los azares de la vida, pero vive para dar valor y fe e inspirar la confianza en el éxito de todas las empresas.

Y cuando esa compañera fiel se ausenta, deja un vacío en el corazón que nada lo llena y el mundo que antes era un vergel lleno de encantos, es hoy un campo desierto lleno de sombras ${ }^{56}$.

Este ejemplo nos remite a la cuestión de que una de las formas de arte que pudiera llamarse con mayor propiedad como "masónicas" es la de los monumentos fúnebres con iconografía propia de las logias, acorde al ceremonial masónico o haciendo analogías con los rituales contenidos en las liturgias de los ritos Escocés y Nacional Mexicano. Así pues, en los panteones de los Ángeles y de la Cruz, encontramos varias tumbas con el símbolo masónico por excelencia del paso al otro mundo, como es precisamente la columna rota ${ }^{57}$; aunque en el caso de Aguascalientes, todo indica que se trató de la forma en que los varones honraron a sus esposas o madres, pues la mayoría de los monumentos funerarios de masones reconocidos como tales, no brindan muchas pistas de su filiación, tal vez porque los familiares supervivientes no lo sabían o no quisieron mostrarla.

En algunos casos, como las tumbas de los hijos del masón Manuel Gómez Portugal Rangel -Jesús y Enriqueta Gómez Portugal Güinchard-, apreciaremos construcciones arquitectónicas más bien neutras o con una simbología un tanto difusa. En el caso de Jesús, por ejemplo, se limita a una especie de esfera en un pináculo, que podría aludir al remate celestial que sobre una de las columnas principales de los templos masónicos se coloca. En cuanto a la tumba de Enriqueta, podría compararse con un altar masónico o ara, aunque desafortunadamente está demasiado deteriorada como para conocer si tuvo elementos ornamentales adicionales.

También es común que las lápidas ostenten símbolos cristianos, a veces con tímidas alusiones a la simbología usada en las logias, como relieves con hojas de palma o mejor dicho, de acacia, madera sagrada del judaísmo, "símbolo masónico de la inmortalidad del espíritu, debido a su verdor renovado y persistente en medio de las arenas desérticas” ${ }^{2}$. En el Manual de Andrés Cassard, especifica que en las exequias de un masón se debe circular una bandeja con siemprevivas, para que los hermanos asistentes tomen alguna con la mano derecha y la arrojen sobre el féretro ${ }^{59}$. Se entiende que esta planta perene, al igual que la acacia, mantiene su verdor, simbólico de la inmortalidad y por ende, del ideal masónico.

\footnotetext{
56 Jesús Díaz de León, “¡Todo acabó!”, El Instructor, año XVI, no. 3, julio de 1899.

57 En el ritual masónico público para realizarse en el cementerio, el venerable maestro pronuncia estas palabras: "Su columna está rota y vacío el sitio que ocupaba en las horas propicias y secretas de nuestras filosóficas meditaciones": Liturgia del Grado de Aprendiz (México DF: Herbasa, 2002), 132.

58 Diccionario breve, 11.

59 Andrés Cassard, Manual de la Masonería, o sea, El tejador de los Ritos Antiguo Escocés, Francés y de Adopción (Nueva York: Appleton y Compañía, 1871), tomo I, 134.
} 
Ante la escasez de documentación masónica regional del siglo XIX, el autor del presente texto ha tomado como indicios de participación en los templos decorados con la escuadra y el compás, las oraciones fúnebres de masones locales a personajes liberales, donde se hacen menciones laicas a la divinidad, propias del discurso masónico, así como referencias a ramos de siemprevivas, como los casos de Francisco G. Hornedo, Isidro Calera, Blas Elizondo y José Bolado.

\section{Conclusiones}

Por si no quedara claro, particularmente en el periodo en que el presidente Porfirio Díaz encabezara la masonería mexicana, los integrantes de logias formaron vínculos muy estrechos. Es el caso de las logias simbólica y filosófica que llevaron el nombre "Primo Verdad", que tuvieron entre sus integrantes a algunos de los personajes ya mencionados, que ostentaron puestos gubernamentales y que además estuvieron emparentados. Por ejemplo, José Herrán y Bolado era primo de la esposa del doctor Jesús Díaz de León, Ángela Bolado, y estuvo casado con Josefa Güinchard. La hermana de esta última, Evangelina Güinchard, se casó con el doctor Manuel Gómez Portugal.

En cuanto a las otras hermanas de Ángela Bolado, se casaron con personajes que fueron gobernadores de Aguascalientes, el primero de ellos con certeza masón, Francisco Hornedo ${ }^{60}$, quien contrajo matrimonio con María del Carmen, y Carlos Sagredo García Rojas - liberal, sin datos de pertenencia a alguna logia-, quien celebró nupcias con Josefa ${ }^{61}$. En cuanto a Julia Delhumeau, fue madrastra de Ángela. Antonia López, por su parte, fue esposa de Rafael Ignacio Chávez, hermano de José María Chávez, quien tuvo como primera cónyuge a Antonia Acosta y López de Nava, de la familia que ya hemos mencionado también.

Con respecto a la genealogía Terán Arteaga-Pani, el masón escocés Jesús Terán no tuvo descendencia, pero tuvo como continuadora de su linaje a su sobrina, Paz Arteaga Terán, quien se casó con el italomexicano Julio Pani, quien a su vez también fue miembro de la élite social y política de Aguascalientes. De él desconocemos alguna filiación masónica, pero por lo menos uno de sus hijos, Camilo Pani, aparece en los listados de masones escoceses de altos grados a principios del siglo XX. De hecho, los hijos de Pani promovieron la repatriación de los restos del diplomático masón que falleciera en París en 1866.

Por motivos de espacio no mencionamos a otros actores descendientes de las genealogías masónicas que tuvieron espacios destacados en la cultura ya en el siglo XX. Es el caso de Ezequiel A. Chávez, quien fue rector de la Universidad Nacional, o Saturnino Herrán, pintor precursor del nacionalismo mexicano. También podemos mencionar al músico Carlos Chávez, nieto de José María Chávez, o al escritor de Farabeuf, Salvador Elizondo, hijo de su padre con el mismo nombre y fundador de los estudios cinematográficos CLASA, descendiente de las genealogías liberales de Aguascalientes Elizondo Sagredo y Pani Arteaga-Terán. También habrá que sumar a los editores Velázquez Chávez, Loera Chávez y otros, además de todas las familias

60 La deducción de su iniciación es por los proyectos que emprendieron masones y que él apoyó, por las palabras que se le dedicaron en su funeral y por una serie de atributos iconográficos polisémicos (ilustración, herramientas masónicas) contenidos en un retrato de época que se conserva de él.

Ramírez Hurtado, “Ángela Bolado y Jesús Díaz de León”, 161. 
de tipógrafos e impresores emparentadas entre sí: Rodríguez Romo, Pedroza, Antúnez y Cornejo, con varios masones entre sus filas.

Salvo algunas excepciones, en general se observa una participación conservadora de la mujer en la vida pública, salvo en raras excepciones donde apoyaron a sus esposos o parientes en actividades fuera de lo convencional, como las exposiciones de arte. No tenemos evidencia de iniciadas en la masonería en Aguascalientes en el siglo XIX, pero sí de cierta relación con masonas prominentes durante la época de la Gran Dieta bajo la dirección de Porfirio Díaz.

El historiador François Xavier Guerra explica en el preámbulo de su libro México: del Antiguo Régimen a la Revolución, que construyó un abultado corpus con las biografías de cientos de personas, para posteriormente establecer las relaciones entre ellas. El mismo define vínculo como "la formalización de las relaciones entre los actores visibles y el funcionamiento del sistema político." En otras palabras, la relación, siempre fechada, de un actor con otros actores: parentesco, amistad, enemistad, solidaridades sociales, relaciones militares, lazos de clientela, etcétera ${ }^{62}$.

El hispanofrancés comparte con otros autores, como Michel Crozier, la idea de que el poder proviene de las relaciones y no necesariamente de que sea un atributo de los actores ${ }^{63}$. En ese sentido, comprender las redes sociales, entendidas estas como las relaciones entre individuos, permite desentrañar la forma en que se ejerció el poder en un momento determinado, como el porfiriato; en este caso, con las sociabilidades locales que se entreveraban entre lo familiar, masónico y político.

Por lo anterior, ahora se puede entender la endogamia familiar de la pequeña burguesía de Aguascalientes, pero también se aclaran sus estrechas relaciones intelectuales, políticas y culturales, y en no pocos casos, el apoyo mutuo que se prodigaron. De hecho, considero muy revelador cómo Valentín Gómez Farías mantuvo comunicación e influencia sobre los círculos liberales de Aguascalientes, lugar en el que inició su carrera como médico y luego como político, además de casarse y establecer vínculos sociales que no siempre fueron visibles, pero permanecieron hasta consumada la Reforma.

A veces se deja de ver en biografías de personajes prominentes que las esposas, madres e hijas de masones, tuvieron una función importante en el desarrollo y apoyo a los varones, lo cual no necesariamente se limitó a ser como en la antigüedad, la unión de linajes. En el caso de la historia de la masonería, queda claro que no debemos desatender la participación o función de las mujeres, ya que pueden presentarse erratas o sesgos al concentrarse solamente en la vida interna de las logias o escribir biografías desde el actuar político y otras esferas pensadas desde lo "masculino".

62 François-Xavier Guerra, México: del Antiguo Régimen a la Revolución (México DF: Fondo de Cultura Económica, 2012), tomo I, 21.

63 Guerra, México: del Antiguo, tomo I, 126. 
REHMLAC+, ISSN 2215-6097, vol. 12, nos. 1-2, julio 2020 / diciembre 2020

\section{Fuentes}

\section{Archivos}

Archivo Histórico del Estado de Aguascalientes.

Archivo Histórico del Estado de Zacatecas.

Biblioteca Pública Central Centenario Bicentenario de Aguascalientes, Archivo Alejandro Topete del Valle.

Universidad de Texas, Colección Latinoamericana Nettie Lee Benson.

\section{Dictiotopografía}

Castro, Marcelo Ferrando. "Las Musas griegas", RedHistoria, 18 de marzo de 2018.

https://redhistoria.com/mitologia-griega-las-musas-griegas/

\section{Hemerografía histórica}

El Artesano. Manual Enciclopédico de Industria y Artes. Aguascalientes.

El Fandango. Periódico político y demócrata. Aguascalientes.

El Instructor, periódico científico y literario. Aguascalientes.

El Republicano. Periódico oficial del Estado de Aguascalientes.

\section{Repositorios digitales}

ancestry.com

familysearch.org

geneanet.org

\section{Bibliografía}

Buchanan, Elizabeth y Pilar, González. Cartas a fesús Terán. Aguascalientes: Instituto Cultural de Aguascalientes, 1998.

Cassard, Andrés. Manual de la Masonería, o sea, El tejador de los Ritos Antiguo Escocés, Francés y de Adopción. Nueva York: Appleton y Compañía, 1871.

Connell, R. W. Masculinidades. México DF: Universidad Nacional Autónoma de México, 2003. 
Díaz de León, Jesús. La Exposición de Bellas Artes en Aguascalientes Correspondiente Al XXIX Certamen Celebrado por el Estado. México DF: José J. López impresor, 1891.

Diccionario breve de la Masonería. Madrid: Fundación María Deraismes, 2010.

De Alba, Pedro. “José María Chávez”. En Letras sobre Aguascalientes. Editado por Antonio Acevedo Escobedo. México DF: Libros de México, 1981 [1963].

De Alba, Pedro. "Jesús Terán, un gran señor de la Reforma”. En Letras sobre Aguascalientes. Editado por Antonio Acevedo Escobedo. México DF: Libros de México, 1981 [1963].

Flores Zavala, Marco Antonio. "El grupo masón en la política zacatecana, 1880-1914”. Tesis de maestría en historia, El Colegio de Michoacán, 2001.

Guerra, François-Xavier. México: del Antiguo Régimen a la Revolución. México DF: Fondo de Cultura Económica, 2012.

Martínez Moreno, Carlos Francisco. “Masonerías, intervencionismo y nacionalismo en México”. Tesis de doctorado en historia, Universidad Nacional Autónoma de México, 2016.

Mora Ruiz, José María. “Obra de Jesús Terán a 125 años de su muerte”. En Memoria. Homenajes a Fesús Terán. Editado por Guadalupe Appendini. México DF: Gobierno del Estado de Aguascalientes, 1991.

Liturgia del Grado de Aprendiz. México: Herbasa, 2002.

López, Jesús F. Pot pourri. Aguascalientes: Imprenta de El Águila, 1897.

Paredes Quiroz, Lourdes Adriana. "Arte funerario en Aguascalientes 1875-1930. La visión sobre la muerte, los discursos visuales: conmemoración y creencias”. Tesis de maestría en investigaciones sociales y humanísticas, Universidad Autónoma de Aguascalientes, 2018.

Ramírez Hurtado, Luciano. "Ángela Bolado, artista de provincia; su influencia en Saturnino Herrán. Atmósfera artística en Aguascalientes, buenas costumbres y élite socio-cultural durante el porfiriato”. Aguascalientes. 2018.

Ramírez Hurtado, Luciano. “Ángela Bolado y Jesús Díaz de León. Una pareja de la élite artística y cultural en el Aguascalientes porfiriano”. En fesús Díaz de León (1851-1919). Un hombre que trascendió su época. Coordinado por Luciano Ramírez Hurtado. Aguascalientes: Universidad Autónoma de Aguascalientes, 2019.

Rojas, Beatriz. Las instituciones de gobierno y la élite local. Aguascalientes del siglo XVII hasta la Independencia. Zamora: El Colegio de Michoacán, 1998. 
Wright de Kleinhans, Laureana. Mujeres notables mexicanas. México DF: Secretaría de Instrucción Pública y Bellas Artes / Tipografía Económica, 1910.

Zalce y Rodríguez. Luis J. Apuntes para la historia de la masonería en México. México DF: edición de autor, 1959. 
REHMLAC+, ISSN 2215-6097, vol. 12, nos. 1-2, julio 2020 / diciembre 2020 